\title{
Use of the Airtraq®optical laryngoscope for nasotracheal intubation in predicted difficult airway management in oral surgery
}

\author{
Manuel Ángel Gómez-Ríos, MD • \\ Laura Nieto Serradilla, MD
}

Received: 9 September 2010/ Accepted: 9 September 2010/Published online: 2 October 2010

(C) Canadian Anesthesiologists' Society 2010

\section{To the Editor,}

Nasotracheal intubation is usually required in oral surgery to allow an unrestricted surgical approach. The standard method is generally performed using the Macintosh laryngoscope supported by Magill forceps. ${ }^{1}$ However, it is recommended to perform awake tracheal intubation in situations where a difficult airway is predicted, a scenario where this technique may be poorly tolerated by the patient. Although fibreoptic intubation is considered the "gold standard", sometimes it is difficult to perform and, therefore, alternatives are necessary. The Airtraq ${ }^{\circledR}$ NT (Prodol Meditec S.A., Vizcaya, Spain) is designed specifically for nasotracheal intubation. We present the successful use of this device in an airway that was considerably distorted due to prior multiple surgeries and radiation therapy. The patient gave written informed consent for publication of this article.

The patient was a 60 -yr-old, $65 \mathrm{~kg}$ male with oropharyngeal cancer and ischemic heart disease. He had undergone four previous surgical interventions involving three reconstructions with a muscle flap for epidermoid carcinoma in different locations of the mouth (submandibular gland, left retromolar triangle, and left vestibule). He was scheduled for excision of a recurrent tumour on the floor of his mouth. Preoperative airway assessment included a Mallampati class IV, a 2-cm interincisor gap, a 5-cm thyromental distance, Upper Lip Bite Test class III with limited cervical hyperextension, and

M. Á. Gómez-Ríos, MD ( $₫)$

Complejo Hospitalario Universitario A Coruña, Coruña, Spain

e-mail: magoris@hotmail.com

L. Nieto Serradilla, MD

Complejo Hospitalario Universitario de Vigo, Vigo, Spain lingual retraction. The Airtraq NT was inserted after standard monitoring, pre-oxygenation with a facemask, administration of a nasal vasoconstrictor, topical anesthesia of the naris and nasopharynx, and sedation with midazolam $1 \mathrm{mg} i v$ and infusion of remifentanil $0.15 \mu \mathrm{g} \cdot \mathrm{kg}^{-1} \cdot \mathrm{min}^{-1}$. After observing a distorted airway, the patient's vocal cords were visualized with a Cormack-Lehane grade II glottic view. A size 6.0 flexible endotracheal tube, previously inserted through the patient's right nostril, passed on first attempt without requiring the use of Magill forceps or additional maneuvers (Figure, Panels B and C). Correct positioning of the endotracheal tube was confirmed by capnography before proceeding to anesthetic induction. The procedure was carried out without incident, and the patient's trachea was extubated at the end of the operation while he was awake.

Oral cancer may lead to airway difficulties resulting from pathologic changes of the oral anatomy or from cancer therapies, such as surgery and radiotherapy. The original Airtraq device was developed for orotracheal intubation and has been proven effective in patients with difficult airways. The original Airtraq has an intubation channel guide, making it impossible to introduce a tube through the nose despite various attempts to adapt its use to nasotracheal intubation. ${ }^{2-5}$ The Airtraq NT was designed to overcome this difficulty, as it is devoid of the posterior channel wall, which provides the additional space needed to facilitate the passage of the tube while still maintaining the original advantages (Figure, Panel A). The anatomically-shaped blade allows a direct route to the tracheal inlet, which facilitates visualization of the glottis and passage of the tube without having to align the oral, pharyngeal, and laryngeal axes or distort the airway structures. It therefore requires less nasotracheal tube manipulation with the Magill forceps. In cases where there are 
Figure A) Adult and pediatric Airtraq ${ }^{\circledR}$ NT laryngoscopes (both devices devoid of the posterior channel wall).

B) Clinical procedure of nasotracheal intubation using the Airtraq ${ }^{\circledR}$ NT laryngoscope. C) Patient after the nasotracheal intubation, prior to surgery
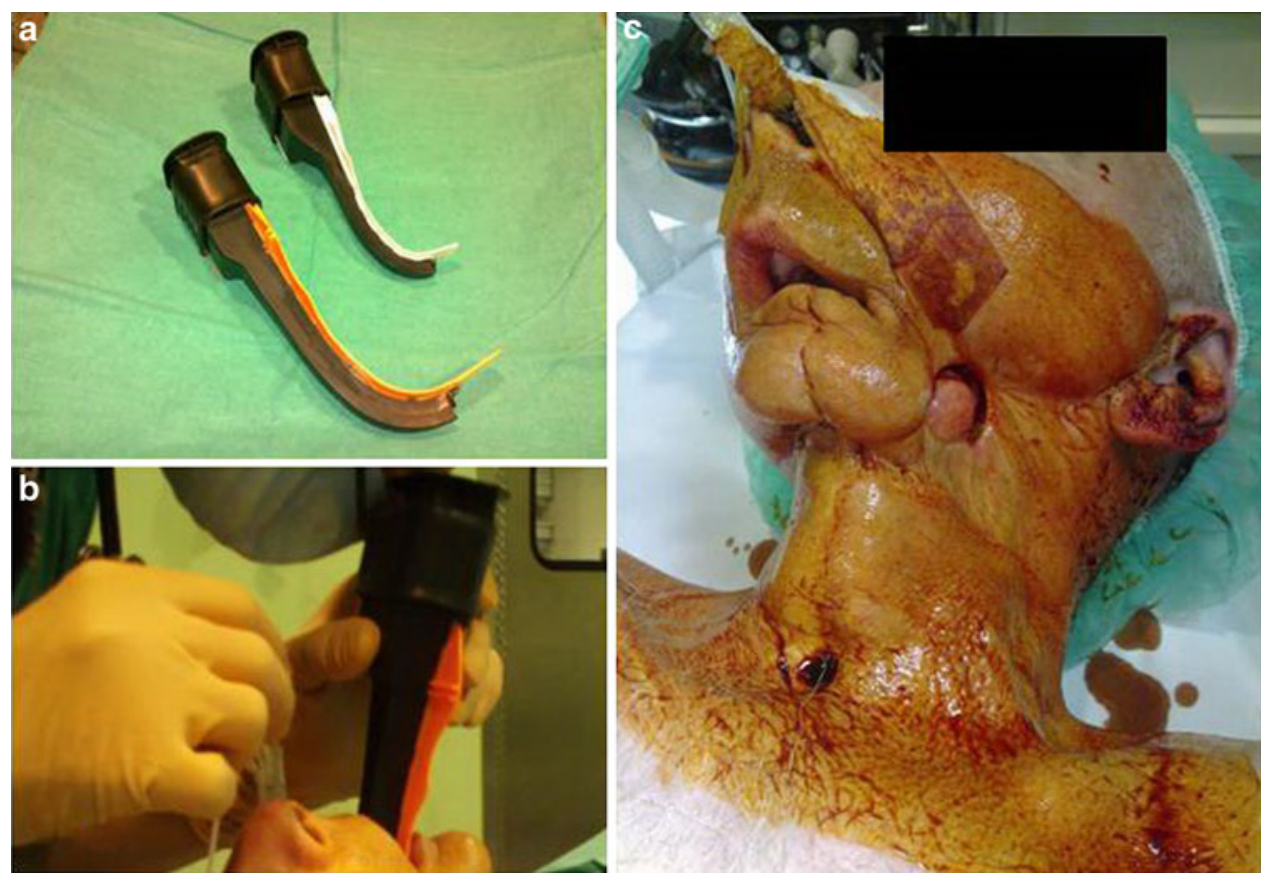

difficulties in directing the tube tip into the visualized glottis, the following techniques can help to solve this problem: external manipulation of the larynx; use of Magill forceps; inflation of the cuff until the tube tip is aligned with the glottis, followed by de-inflation; or combined use with the fibrescope inserted through the nasotracheal tube. Therefore, we choose to use a flexible tube rather than a preformed nasal tube so that the fibrescope could pass through in such a situation. In one published case report, use of the Airtraq ${ }^{\circledR}$ NT is described in a different difficult airway scenario in which flexible bronchoscopy failed. ${ }^{6}$

In our case, this optical laryngoscope was well tolerated by the patient, and it allowed us to maintain an appropriate level of patient comfort and hemodynamic stability throughout the process to facilitate this procedure. We consider the Airtraq ${ }^{\circledR}$ NT an effective alternative to nasotracheal intubation in patients with difficult airways.

\section{References}

1. Hall CE, Shutt LE. Nasotracheal intubation for head and neck surgery. Anaesthesia 2003; 58: 249-56.

2. Xиe FS, Liu JH, Yuan YJ, Liao X, Wang Q. Cuff inflation as an aid to nasotracheal intubation using the Airtraq laryngoscope. Can J Anesth 2010; 57: 519-20.

3. Morris CJ, Rangasami J, Asai T. Paediatric Airtraq for adult nasal intubation in anaesthetized patients. Br J Anaesth 2010; 104: 506-7.

4. Hirabayashi $Y$, Seo N. Airtraq laryngoscope has an advantage over Macintosh laryngoscope for nasotracheal intubation by novice laryngoscopists. J Anesth 2009; 23: 172-3.

5. Hirabayashi $Y$, Seo N. Nasotracheal intubation using the Airtraq versus Macintosh laryngoscope: a manikin study. Anesth Prog 2008; 55: 78-81.

6. Schoettker P, Bathory I, Broome M. Use of the nasotracheal Airtraq to assist difficult nasal fibreoptic intubation. Can J Anesth 2008; 55: 884.

Competing interests None declared. 